\title{
Analisis pemotongan logam ST-37 dengan mesin potong menggunakan gas oxy-LPG
}

\author{
Ade Irvan Tauvana ${ }^{1^{*}}$, Widodo ${ }^{2}$ \\ 1,2Prodi Teknik Mesin Politeknik Enjinering Indorama \\ Jl. Kembangkuning, Jatiluhur, Purwakarta-Jawa Barat 41152 \\ Email: ade.irvan@pei.ac.id ${ }^{1}$, widodo@pei.ac.id²,
}

\begin{abstract}
This gas cutting machine is an ST-37 metal cutting tool in a semi-automatic way using Liquified Potroleum Gas (LPG) and Oxygen gas materials. LPG gas is used with a composition of propane $80 \%$ and Isobutane $20 \%$. In the process of cutting metal based on several parameters, namely: metal thickness, oxygen gas pressure, and LPG gas and cutting speed. Before cutting down the metal, the preparation stage is done by conditioning the test equipment and work equipment used to collect test data. The method used in this research is to select the type of metal and cutting equipment then do the recording and taking test data. Further analysis and examination are carried out as follows: visual inspection of the results of cutting and flame shape, a better composition results from testing in accordance with applicable rules such as pressure, plate thickness, and time of cutting. $80 \%$ and $20 \%$ LPG gas composition at gas working pressure: $0.2 \mathrm{~kg} / \mathrm{cm}^{2}$, oxygen pressure: $2.5 \mathrm{~kg} / \mathrm{cm}^{2}$, cutting distance of $2 \mathrm{~mm}$. The results of this test are overall in good condition and no defects occur.
\end{abstract}

Keywords: LPG gas cutting, propane, isobutane, cutting speed, oxygen.

\section{Abstrak}

Gas cutting machine ini adalah alat pemotong logam ST-37dengan cara semi otomatis menggunakan bahan Liquified Potroleum Gas (LPG) dan Oksigen. Gas LPG yang digunakan dengan komposisi propane $80 \%$ dan Isobutan $20 \%$. Dalam melakukan proses pemotongan logam harus memperhatikan beberapa parameter yaitu: tebal logam, tekanan gas oksigen dan gas LPG dan kecepatan pemotongan. Sebelum melakukan pemototongan logam terlebuh dahulu dilakukan tahap persiapan dengan mengkondisikan peralatan uji dan peralatan kerja yang digunakan untuk pengambilan data pengujian. Metode yang digunakan dalam penelitian ini adalah melakukan pemilihan jenis logam dan peralatan potong selanjutnya dilakukan pencatatan dan pengambilan data uji. Selanjutnya dilakukan Analisa dan pemeriksaan sebagai berikut: pemeriksaaan visual dari hasil pemotongan dan bentuk nyala api, komposisi yang lebih baik hasil dari pengujian sesuai dengan kaidah yang berlaku seperti tekanan, tebal pelat dan waktu pemotongan. Komposisi gas LPG $80 \%$ dan $20 \%$ pada tekanan kerja gas: $0,2 \mathrm{~kg} / \mathrm{cm}^{2}$; tekanan oksigen; $2.5 \mathrm{~kg} / \mathrm{cm}^{2}$, jarak pemotongan $2 \mathrm{~mm}$. Hasil pengujian ini secara keseluruhan dalam kondisi baik dan tidak terjadi cacat.

Kata kunci: LPG gas cutting, propane, isobutane, kecepatan potong, oksigen.

\section{Pendahuluan}

Gas cutting machine adalah salah satu jenis mesin pemotong yang bisa memotong plat baja dengan baik ketepatan. Prinsip-prinsip mesin pemotong ini menggunakan pengelasan oksifuel. Mesin ini memiliki dimensi sederhana, aplikasi, dan pemeliharaan [1].
Berdasarkan hasil analisis data didapatkan nilai kecepatan rata-rata potong alat las potong portable pada pemotongan plat besi dengan tebal $5 \mathrm{~mm}$ adalah 0,26 $\mathrm{cm} /$ detik untuk pemotongan melintang dan 0,299 $\mathrm{cm} /$ detik untuk pemotongan membujur. Semakin tebal plat besi, semakin lama kecepatan yang dibutuhkan 
dan semakin besar kalor serta tekanan gas yang digunakan dalam proses pemotongan [2].

Proses oxyfuel adalah proses pemotongan termal industri yang paling banyak diterapkan karena dapat memotong ketebalan dari $0,5 \mathrm{~mm}$ hingga $250 \mathrm{~mm}$, peralatan ini berbiaya rendah dan dapat digunakan secara manual atau mekanis. Ada beberapa pilihan desain bahan bakar gas dan nozzle yang dapat secara signifikan meningkatkan kinerja dalam hal kualitas potong dan kecepatan potong [3].

Menggunakan mesin pemotong profil gas otomatis dapat memotong lembaran logam pemotong $1800 \mathrm{~mm} \times 150$ mm dengan ketebalan dalam kisaran 6-100 $\mathrm{mm}$. Mesin pemotong profil gas otomatis memberikan tingkat produksi yang lebih tinggi, penyimpanan inventaris yang lebih terorganisir, dan kemudahan akses pada saat yang sama [4]. Pengaruh parameter pemotongan pada kualitas permukaan dilaksanakan oleh hasil eksperimen yang diperoleh dari pemotongan pelat baja nonGalvanis ASTM BN 1323 dalam parameter pemotongan yang berbeda (kecepatan potong, waktu pemanasan awal, dan ketebalan pelat) diikuti oleh tidak rusak (kekerasan dan kekasaran permukaan). Cutting surface menguji untuk menyelidiki kontrol kualitas pada spesimen potong [6].

\section{Tinjauan Pustaka}

\section{Pemotongan Plat}

Pemotongan plat dengan gas ini termasuk dalam bidang teknologi pengelasan dimana prinsipnya adalah dengan mencairkan logam. Baja dipanaskan sampai merah cemerlang (sekitar $875^{\circ} \mathrm{C}$ ) kemudian disemburkan gas pemotong dengan tekanan yang tinggi untuk menembus baja tersebut. Pemotongan ini dilakukan dengan mengarahkan aliran oksigen ke bagian yang akan dipanaskan dimana kemudian terjadi proses laju oksidasi yang kencang (semburan). Semburan oksidasi ini kemudian dikenal sebagai pemotongan oksiasetilen (cutting oxiacetylene).
Perkembangan selanjutnya yang terjadi bahwa pemotongan ini tidak hanya dioperasikan secara manual tetapi juga dengan mesin (gas cutting machine).

2. Karakteristik Baja St 37 (AISI 1045)

Baja St 37 adalah baja karbon sedang yang setara dengan AISI 1045, dengan komposisi kimia Karbon: $0.5 \%$, Mangan: $0.8 \%$, Silikon: $0.3 \%$ ditambah unsure lainnya.Dengan kekerasan \pm 170 HB dan kekuatan tarik $650-800 \mathrm{~N} / \mathrm{mm}^{2}$. Secara umum baja ST 37 dapat digunakan langsung tanpa mengalami perlakuan panas, kecuali jika diperlukan pemakaian khusus.

\section{Gas Cutting Machine}

Unit mesin Gas Cutting Machine menggunakan gerak dari tenaga listrik yang dialirkan ke motor listrik pada mesin, mesin ini dapat bergerak maju dan mundur pada rel yang digunakan untuk landasan jalan agar gerak mesin lurus dan stabil dengan kecepatan yang dapat diatur pada bagian panel adjust speed sesuai dari ketebalan pelat yang akan dipotong. Pelat yang dapat dipotong oleh mesin ini berukuran tebal 6-100 mm. Gambar mesin terlihat pada Gambar 1.

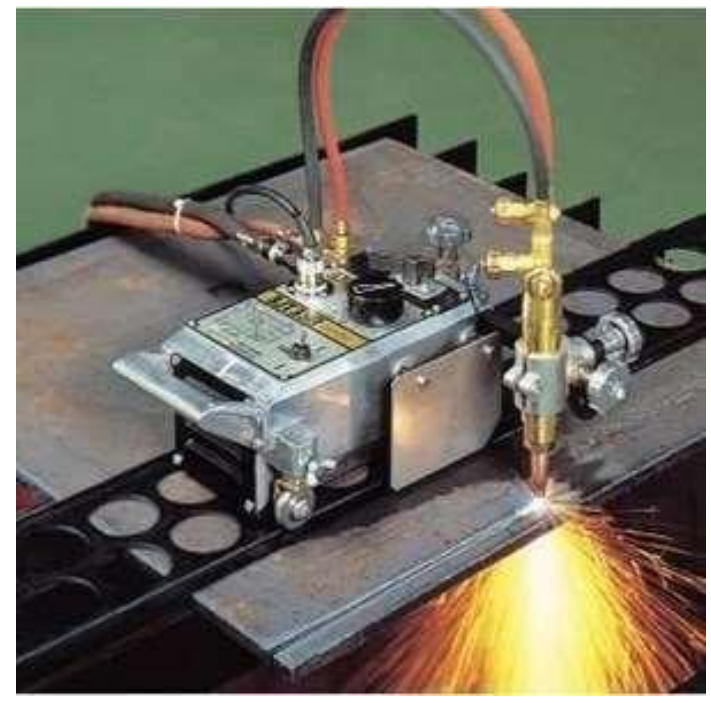

Gambar 1. Desain alat gas cutting semi otomatis [5] 
Tabel 1. Spesifikasi mesin gas cutting semi otomatis

\begin{tabular}{|c|c|}
\hline Type & CG1-30 \\
\hline Cutting Speed & $50-750 \mathrm{~mm} / \mathrm{mnt}$ \\
\hline Cutting & $5-100 \mathrm{~mm}$ \\
\hline Effedive Cutting & $200-2000 \mathrm{~mm}$ \\
\hline Power source & AC $220 \mathrm{~V} 50 \mathrm{HZ}$ \\
\hline Weight & 16 kilogram \\
\hline Machine & $435 \mathrm{~mm} \times 210 \mathrm{~mm} \times 240 \mathrm{~mm}$ \\
\hline Speed control & Silicon control \\
\hline Groove angle & $0-45$ degrees \\
\hline Nozzle & G02 (acetylene) $\quad \mathrm{G} 03$ \\
\hline Motor & DC $\quad 110 \mathrm{~V} \quad 50 \mathrm{HZ} \quad 30 \mathrm{~W}$ \\
\hline
\end{tabular}

\section{Gas Propane}

Propane adalah hasil dari ikatan tambang minyak dan gas alam gas ini disimpan dalam tabung baja dengan kapasitas $45 \mathrm{~kg}$ pada kondisi cair. Oleh karena itu lebih dikenal dengan nama LPG (Liquified Potroleum Gas). Dalam bentuk alami, propane tidak berwarna dan tidak berbau. Untuk membuat propane lebih mudah dideteksi jika terjadi kebocoran atau tumpahan, produsen menambahkan senyawa kimia untuk memberikan bau yang khas. Gas ini memang tidak sesuai untuk bahan bakar las tetapi baik bila dipakai sebagai bahan bakar potong, brassing maupun soldering.

Propana mengalami reaksi pembakaran yang mirip dengan alkana lain. Pada keadaan oksigen berlebih, propana terbakar dan membentuk air dan karbon dioksida.

$\mathrm{C}_{3} \mathrm{H}_{8}+5 \mathrm{O}_{2} \rightarrow 3 \mathrm{CO}_{2}+4 \mathrm{H}_{2} \mathrm{O}+$ panas propana + oksigen $\rightarrow$ karbon dioksida + air

\section{Gas oksigen}

Gas oksigen ini digunakan untuk campuran gas karbit pada proses penyalaan api las. Banyak ataupun sedikit penggunaan gas oksigen ini akan berpengaruh pada suhu pembakaran. Bila gas oksigen ini lebih sedikit dari pada gas karbit maka akan berakibat suhu pembakarannya rendah. Tabung oksigen mempunyai kapasitas sama dengan tabung gas acetylene. Isi gas dalam tabung berbanding lurus dengan tekanan, makin besar tekanan makin banyak isi di dalamnya. Untuk membedakan tabung gas oksigen dengan tabung gas lainnya, maka tabung gas oksigen diberi warna biru, hijau atau abu-abu dan terkadang juga diberi warna hitam.

Sebelum melakukan pengambilan data terlebih dahulu melakukan perakitan alat, pemasangan rel dan persiapan alat ukur, regulator untuk mengetahui tekanan gas dan stop watch.

Gas Cutting Machine mempunyai bagian-bagian utama untuk melakukan proses pemotongan (Gambar 2).

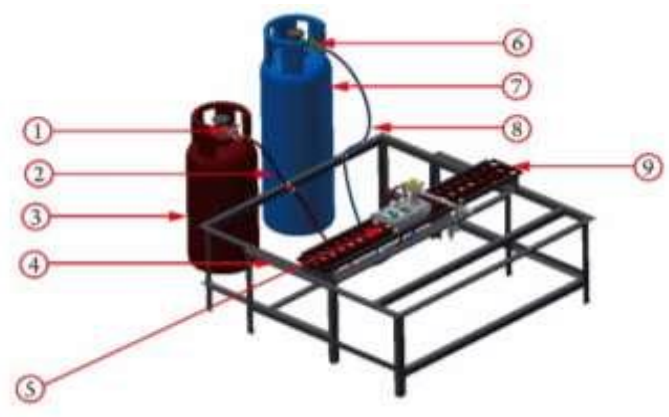

Gambar 2. Bagian-bagian utam mesin potong Gas.

Keterangan Gambar 2:

1. Regulator bahan bakar

2. Hose bahan bakar

3. Tabung bahan bakar

4. Meja gas cutting machine

5. Gas cutting machine

6. Regulator

7. Tabung oksigen

8. Hose oksigen

9. Rell mesin

\section{Metode Penelitian}

Bahan yang digunakan dalam penelitian ini adalah gas oksigen dan LPG

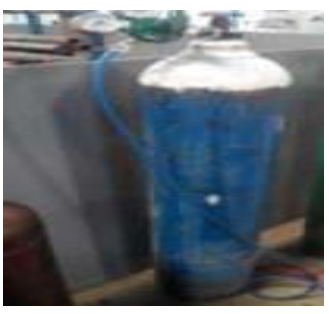

(a)

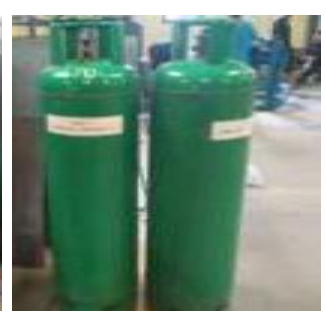

(b)
Gambar 3.(a) Gas oksigen (b) Gas $L P G$

Penelitian ini dilakukan di Lab. Pengelasan Teknik Mesin Politeknik Enjinering Indorama. Jenis mesin yang 
dipakai adalah Gas Cutting Machine type CG-30. Sedang plat baja yang digunakan adalah tipe Baja ST 37. Dimensi plat baja yang digunakan yaitu:

Tebal $3 \mathrm{~mm}$; Panjang plat $40 \mathrm{~mm}$,

Tebal $9 \mathrm{~mm}$; Panjang plat $50 \mathrm{~mm}$,

Tebal $12 \mathrm{~mm}$; Panjang pelat $65 \mathrm{~mm}$.

Saat pengoperasian tekanan oksigen $=2$ $\mathrm{kg} / \mathrm{cm}^{2}$ dan tekanan propan $=0,2 \mathrm{~kg} / \mathrm{cm}^{2}$.

\section{Hasil dan Pembahasan}

1. Pemeriksaaan bentuk nyala api pemotongan

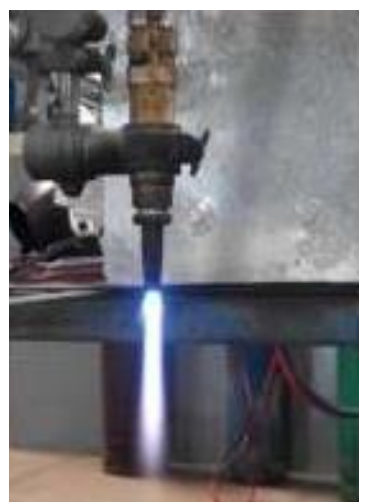

Gambar 4. Bentuk nyala api saat heating

Nyala api free heating yang standar untuk pemotongan yaitu dengan perbandingan propane 1:2 dengan oksigen. Sumbu api luar berukuran 70-120 mm. Sumbu api dalam berukuran 4-7 $\mathrm{mm}$. Bentuk api melebar.

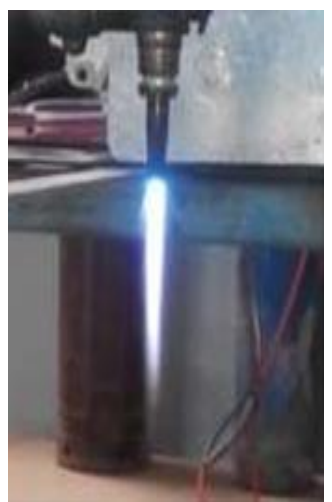

Gambar 5. Bentuk nyala api saat cutting

Nyala api cutting yang standar untuk pemotongan yaitu dengan perpandingan propane 1:2 dengan oksigen Sumbu api luarberukuran 70-130 $\mathrm{mm}$. Sumbu api dalam berukuran 4-7 $\mathrm{mm}$. Bentuk api mengkerucut.
2. Kecepatan potong (cutting speed) terhadap ketebalan pelat

Tabel 2. Hasil Pemotongan Menggunakan Mesin Brander Cutting Semi Otomatis Dengan Bahan Bakar $O x y-L P G$

\begin{tabular}{|c|c|c|c|c|c|c|c|}
\hline Sampel & $\begin{array}{l}\text { Tebal } \\
(\mathrm{mm})\end{array}$ & Percobaan & $\begin{array}{l}\text { Panjang } \\
(\mathrm{mm})\end{array}$ & $\begin{array}{l}\text { Adjusting } \\
\text { Speed }\end{array}$ & $\begin{array}{l}\text { Waktu } \\
\text { (s) }\end{array}$ & $\begin{array}{l}\text { Rata- } \\
\text { Rata }\end{array}$ & $\begin{array}{l}\text { Kec. } \\
\text { Potong } \\
\text { (mm/s) }\end{array}$ \\
\hline \multirow{12}{*}{$\begin{array}{c}\text { Komposisi } \\
\text { Propane } \\
80 \% \\
\text { Butane } \\
20 \%\end{array}$} & \multirow{3}{*}{3} & 1 & 40 & 6 & 3,4 & \multirow{3}{*}{3,1} & \multirow{3}{*}{11.7} \\
\hline & & 2 & 40 & 6 & 3,3 & & \\
\hline & & 3 & 40 & 6 & 3,6 & & \\
\hline & \multirow{3}{*}{6} & 1 & 50 & 5 & 5,4 & \multirow{3}{*}{5,2} & \multirow{3}{*}{9,6} \\
\hline & & 2 & 50 & 5 & 5,3 & & \\
\hline & & 3 & 50 & 5 & 5,1 & & \\
\hline & \multirow{3}{*}{8} & 1 & 50 & 4 & 7,3 & \multirow{3}{*}{7,2} & \multirow{3}{*}{6,9} \\
\hline & & 2 & 50 & 4 & 7,2 & & \\
\hline & & 3 & 50 & 4 & 7,1 & & \\
\hline & \multirow{3}{*}{12} & 1 & 65 & 4 & 9,4 & \multirow{3}{*}{9,3} & \multirow{3}{*}{4,9} \\
\hline & & 2 & 65 & 4 & 9,2 & & \\
\hline & & 3 & 65 & 4 & 9,5 & & \\
\hline
\end{tabular}

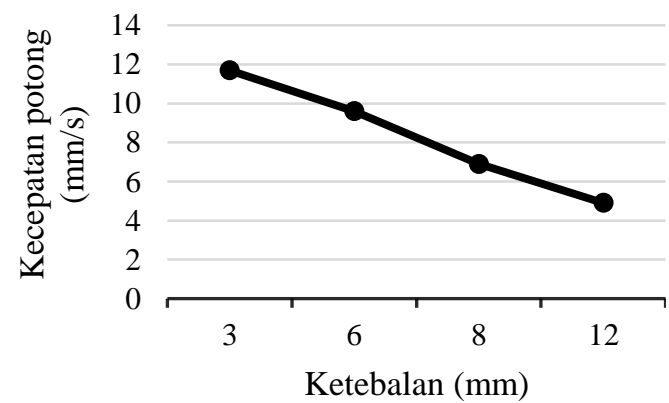

Gambar 6. Hubungan antara kecepatan potong dan ketebalan

Secara keseluruhan dari Gambar 6 dapat dilihat bahwa kecepatan potong tertinggi terjadi pada ketebalan plat $3 \mathrm{~mm}$ dengan nilai sebesar $11,7(\mathrm{~mm} / \mathrm{s})$ kemudian kecepatan terendah terjadi terendah terjadi pada ketebalan $12 \mathrm{~mm}$ dengan nilai.

3. Hasil pemeriksaan visual hasil pemotongan menggunakan gas oxy$L P G$ sebesar $(4,9(\mathrm{~mm} / \mathrm{s})$.

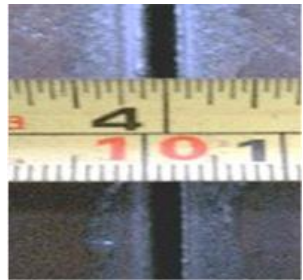

(a)

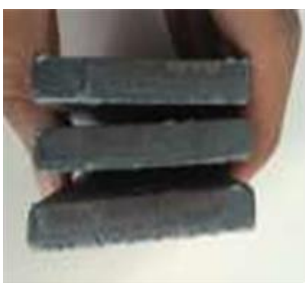

(b)
Gambar.7 a) Ketebalan potongan, b) Visual hasil potongan

Dari gambar 7 (a), tampak bahwa alur pemotongan yang dihasilkan sangat 
rapi dan bersih dari terak dan memiliki lebar yang kecil. Sedangkan pada gambar 7 (b) tampak penampang plat baja hasil pemotongan dimana hasilnya permukaaan penampang yang bagus dan lag (garisgaris tarikan) vertikal yang sangat halus serta pada bagian atasnya agak membulat. Hasil ini didapat karena adanya beberapa faktor yaitu:

1) Kecepatan pemotongan yang tepat. Sesuai dengan tebal plat dan tekanan oksigen serta gas Propane yang pas.

2) Pemilihan ukuran nosel yang cocok serta kondisi orifice nosel yang bersih

3) Permukaan pemotongan tidak terdapat trak pada benda kerja dengan ketebalan $8 \mathrm{~mm}$ ke atas, akan tetapi trak masih ada apabila pelat yang digunakan sangat tipis

4) Jarak yang dihasiilkan dari pemotongan yaitu $2 \mathrm{~mm}$

5) Kondisi campuran bahan bakar dan oksigen mudah diatur.

6) Kondisi nyala api mudah untuk dinyalakan maupun diatur sudut apinya

4. Tekanan terhadap ketebalan pelat

Dari hasil pengujian dengan 4 variasi ketebalan pelat dapat menghasilkan. Tekanan kerja untuk oksigen semakin tebal pelat semakin besar tekanan yang dibutuhkan sedangkan untuk tekanan kerja gas $L P G$ ditetapkan konstan sebesar 0,2 $\mathrm{kg} / \mathrm{cm}^{2}$, lebih jelas dapat dilihat pada Tabel 3.

Tabel 3. Pressure ksigen dan propane

\begin{tabular}{|c|c|c|c|c|c|}
\hline \multirow{2}{*}{$\begin{array}{c}\text { Ketebal } \\
\text { an Pelat } \\
(\mathrm{mm})\end{array}$} & \multicolumn{2}{|c|}{$\begin{array}{c}\text { Tekanan isi } \\
\left(\mathrm{kg} / \mathrm{cm}^{2}\right)\end{array}$} & \multicolumn{2}{|c|}{$\begin{array}{c}\text { Tekanan kerja } \\
\left(\mathrm{kg} / \mathrm{cm}^{2}\right)\end{array}$} & \multirow{2}{*}{$\begin{array}{c}\text { Lebar } \\
\text { Jarak } \\
\text { Potong } \\
(\mathrm{mm})\end{array}$} \\
\hline & oksige & opan & oksigen ${ }^{f}$ & ane & \\
\hline 3 & 70 & 10 & 1 & 0,2 & 2 \\
\hline 6 & 70 & 10 & 1,5 & 0,2 & 2 \\
\hline 8 & 70 & 10 & 2 & 0,2 & 2 \\
\hline 12 & 70 & 10 & 2,5 & 0,2 & 2 \\
\hline
\end{tabular}

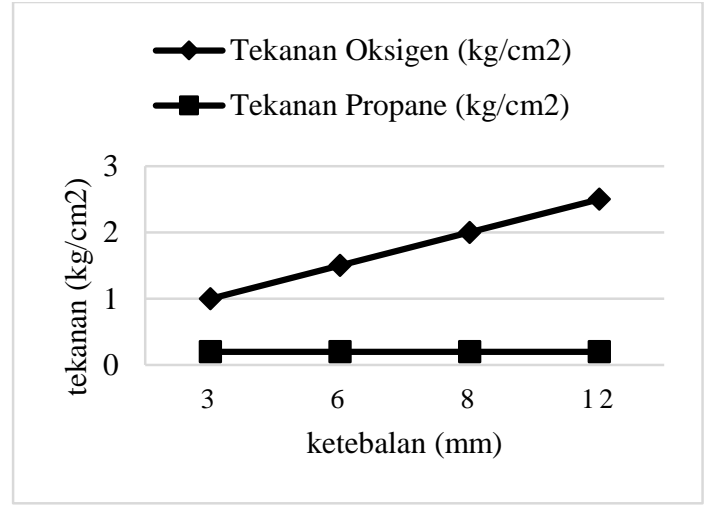

Gambar 8. Hubungan antara tekanan dan ketebalan.

Secara keseluruhan dari gambar 8 . dapat dilihat bahwa tekanan kerja tertinggi terjadi pada tekanan kerja propane 0,2 $\mathrm{kg} / \mathrm{cm}^{2}$; tekanan kerja oksigen $2.5 \mathrm{~kg} / \mathrm{cm}^{2}$. Kemudian tekanan kerja terendah terjadi pada kerja $L P G 0,2 \mathrm{~kg} / \mathrm{cm}^{2}$; tekanan kerja oksigen $1 \mathrm{~kg} / \mathrm{cm}^{2}$ pada ketebalan plat $3 \mathrm{~mm}$.

\section{Kesimpulan}

Semua komposisi dapat dipergunakan untuk proses pemotongan pelat tetapi komposisi terbaik antara adalah $80 \%$ propane dan $20 \%$ butane pada perlakuan tekanan kerja propane 0,2 $\mathrm{kg} / \mathrm{cm}^{2}$; tekanan kerja oksigen $2.5 \mathrm{~kg} / \mathrm{cm}^{2}$; tekanan isi propane $70 \mathrm{~kg} / \mathrm{cm}^{2}$; tekanan isi oksigen $100 \mathrm{~kg} / \mathrm{cm}^{2}$; jarak pemotongan yang di hasilkan $2 \mathrm{~mm}$. Dari hasil pengujian dan analisis yang dilakukan dengan meggunakan visual hasil dari pemotongan, bentuk nyala api, kecepatan potong, dan tekanan gas propanee direkomendasikan sebagai pengganti gas asyteline hanya bisa untuk proses pemotongan (cutting).

\section{Ucapan Terimakasih}

Pada kesempatan ini penulis ingin mengucapkan banyak terima kasih kepada PT. Pertamina yang telah bersedia bekerja sama dengan kami untuk melakukan penelitian ini. Dan semoga dengan adanya penelitian ini akan menjadi referensi baru bagi perkembangan teknologi di masa mendatang dan memberi sedikit masukan Pertamina sendiri. Terima kasih. 


\section{Referensi}

[1]. Syarief Firman Akbar, Bambang Kusharjanta, Pemotongan Plat Baja Dengan Gas Cutting Machine, UNS, 2010

[2]. Adiguna, Indrawan Maulana, Murni, Rancang Bangun Las Potong Portable (Design Of Portable Welding Machine), Universitas Diponegoro, 2015.

[3]. P. Kulkarni, P. Randive, and A. R. Mache, "MicroController based OxyFuel Profile Cutting System", World Academy of Science, Engineering and Technology 47, 2008.

[4]. Ajay M Patel1 Dhaval ShahMudit Kothari, Design and Manufacturing of Automated Gas Profile Cutting Machine using PLC; IJSRD International Journal for Scientific Research \& Development| Vol. 3, Issue 05, 2015 | ISSN (online): 2321061

[5]. Huawei Welding and Cutting. Manual book. Operating Intructions CG1- 30 Gas Cutting Machine. Huawei. Shanghai

[6]. Osamah F, Abdulateef Faiz F. Mustafa and Salah A. Salman, "Prediction the Effect of Flame Cutting Parameters on the Quality of Metal Surface In CNC Flame Cutting Machine Using Artificial Neural Network" The Iraqi Journal For Mechanical And Material Engineering, Vol.10, No.3, 2010.

[7]. Sunaryo, Heri. 2008. Teknik Pengelasan Kapal Jilid 1. Direktorat Pembinaan Sekolah Menengah Kejuruan. Jakarta

[8]. Wahyu Catur N. Wahyu Setyo P. 2016 Sistem Pengaturan Pembukaan Gas Acitelin Dan Oksigen Pada Scator Untuk Pemotongan Plat Baja Seminar Nasional Sains dan Teknologi Terapan IV ISBN 978602-98569-1-0 Institut Teknologi Adhi Tama Surabaya. 